\title{
Exploring in teaching mode of Optical Fiber Sensing Technology outcomes- based education (OBE)
}

Guangwei Fu, Xinghu Fu, Baojun Zhang, Weihong Bi

Guangwei Fu, Xinghu Fu, Baojun Zhang, Weihong Bi, "Exploring in teaching mode of Optical Fiber Sensing Technology outcomes-based education (OBE)," Proc. SPIE 10452, 14th Conference on Education and Training in Optics and Photonics: ETOP 2017, 104526E (16 August 2017); doi: $10.1117 / 12.2269938$

SDIE Event: 14th Conference on Education and Training in Optics and Photonics, ETOP 2017, 2017, Hangzhou, China 


\title{
Exploring in Teaching Mode of "Optical Fiber Sensing Technology" Outcomes-based Education (OBE)
}

\author{
Guangwei Fu*, Xinghu Fu, Baojun Zhang, Weihong Bi \\ School of Information Science and Engineering, The Key Laboratory for Special Fiber and Fiber \\ Sensor of Hebei Province, Yanshan University, Qinhuangdao 066004, China
}

\begin{abstract}
Combining with the characteristics of disciplines and OBE mode, also aiming at the phenomena of low learning enthusiasm for the major required courses for senior students, the course of optical fiber sensing was chosen as the demonstration for the teaching mode reform. In the light of "theory as the base, focus on the application, highlighting the practice" principle, we emphasis on the introduction of the latest scientific research achievements and current development trends, highlight the practicability and practicality. By observation learning and course project, enables students to carry out innovative project design and implementation means related to the practical problems in science and engineering of this course.
\end{abstract}

key words OBE; Practical teaching; Optical fiber sensing; Photo-electron professional; Teaching mode

\section{INTRODUCTION}

Cultivating technology engineers who adapt to the needs of national economic construction not only is the national strong demands to the college graduates in recent years, but also is the market economy demands for engineering talent[1,2]. Compared with developed countries, there is a significant gap in the level of practical teaching in China, especially in engineering practice teaching [3]. The urgent task for our higher engineering education is training Chinese engineers with international standards as soon as possible. However there are many problems in the engineering practice of education in our country, such as issues about emphasis on theory while take little account of practice, thinking highly of individual ability on academics while ignoring the spirit of teamwork, paying much attention to knowledge learning while despising the development of innovation.

Aiming at the phenomena such as low learning enthusiasm, low attendance and poor teaching effect for the senior students, we will make the teaching mode reform design and practice exploring based on the professional course of optical fiber technology, hoping to improve the students' interest in learning, increase their abilities to integrate theory with practice, cultivate their scientific innovation abilities[4,5], which also is an important way to implement the concept of CDIO[6]. In view of this, this paper makes a preliminary exploration and research on the reform and practice of the teaching mode for the professional course of optical fiber sensing technology.

*earl@ysu.edu.cn;

14th Conference on Education and Training in Optics and Photonics: ETOP 2017, edited by Xu Liu,

Xi-Cheng Zhang, Proc. of SPIE Vol. 10452, 104526E · (c) 2017 ICO, IEEE, OSA, SPIE

CCC code: $0277-786 X / 17 / \$ 18 \cdot$ doi: $10.1117 / 12.2269938$ 


\section{THE OBJECTIVE OF THE CURRICULUM REFORM}

Optical fiber sensing technology is a course with strong comprehensiveness, applicability, and practicality. It integrates the knowledge involving optics, mechanical, electronic, computer and other aspects, and also closely relates to production, scientific research practice. According to the characteristics of optical fiber sensing technology, such as, the course covers a wide range and every chapter is independent from others; the course content is much complex for students to find the emphasis and laws, they don't know what should be grasped and how to master it; owing to their insufficient practical knowledge and experience, it is difficult for students to understand well this course. In view of this, on the basis of teaching basic theoretical knowledge, teachers may explain the content of every chapter by showing the basic principle, measuring circuit, application examples of different kinds of sensors.

1) Clear on primary and secondary teaching, properly detailed and concise learning contents for focusing on mastering and general understanding, and increase the latest scientific research results and the development of cutting-edge introduction. During the explanation, combining theory with practice, using two hours to lead the students observe the optical fiber sensing experimental platform in the laboratory, such as fiber grating fabrication platform, distributed optical fiber sensing platform, etc., make students to key grasp in basic theories and the basic principles, at the same time combine with the actual situation, understand optical instruments closely related to optical fiber sensing technology from the sense. If conditions permit, to combine theoretical teaching and practical teaching, each chapter is matching with experiment, so as to improve students' interest in learning.

2) Fully using the advantages of modern electronic teaching methods in teaching. The course characteristic of optical fiber sensing technology is strong applicability and involving a wide range; lots of engineering principles are very difficult to express clearly in words; while writing on the blackboard is time-consuming and laborious, also it can not be dynamically displayed. Using multimedia materials in PPT can resolve the problems that difficult to carry out the actual contents. In order to let students have a glance at some middle processes and improve their learning interests, we need to show a large number of actual cases. In addition, we can also try to deepen students' sensory impression by multimedia playback animation. For example, it is difficult to describe the formation and moving direction of Moire fringe in the optical fiber Bragg grating sensor, but using a animation demonstration, it will be clear at a glance.

3) Adopting flexible evaluation mechanism. If it only use a closed-book examination as the evaluation method in this course, it will lead to lots of students merely pay attention to the theory exam and ignore the combination of theory and practice. So it is very difficult for the students to use the knowledge in practice after they studied the course, that is a phenomenon of disconnection between theory and practice. In the mean time, it also goes against the idea of training applied talents. Therefore, after the completion of teaching, we will arrange students to finish a specific requirement of the optical fiber sensing system design, and encourage them realize the testing system in the lab. Finally, this work score is as a part of the results of the whole course examination, such as the total score $=$ exam score + comprehensive design score + experimental score.

4) Lay emphasis on cultivating students' learning interest. Learning interest is not only an important factor for students to learn the theoretical knowledge, but also an important condition for teachers to achieve good teaching results. Therefore, it is very important to cultivate students' interest in learning. Since an interdisciplinary subject, it is more difficult to learn. The reason is that most of the students forget the previous basic knowledge, leading to the knowledge before and after can not be smoothly linked up, setback in learning interest. So in teaching, on the one hand, replenish the relevant basic theoretical knowledge according to the specific circumstances of the students; On the other hand, combine 
with the usual accumulation of scientific research, cite some real-life examples of a certain type of sensor when introducing. For example, for optical fiber gas sensor, it can refer to "the detection of gas" that students heard about; for the distributed optical fiber sensor, its applications in the field of Aeronautics and Astronautics, security and so on are mentioned. In some of these often used sensors, students will realize that studying this course not only can solve some practical problems, but also can use multiple sensors to achieve many application examples, as a result, stimulate students' creative thinking, and increase their learning interest.

\section{THE SPECIFIC TEACHING CONTENT REFORM}

Based on the principle of "theory as the foundation, focusing on application and highlighting on practice", the content of the course is determined by the demand and development of optical fiber sensing technology, focusing on the introduction of the latest scientific research achievements and the development trend of the frontier, highlighting the practicality and practicality. The course contents are organized as follows:

1) Adopt the method of making the focal stand out, step by step, theory design before practice when constructing the teaching content; divide the course into four main stages, namely the basic knowledge and principle stage, observing learning stage, designing for application stage, and comprehensive application stage.

2) Highlight the key technologies, emphasize design ideas. According to the practical characteristics of the optical fiber sensing technology, combine with the actual demands of the industry, by means of centralized classification teaching, and place emphasis on the specific application, pay attention to cultivating students' divergent thinking and innovation, which pay attention to the cultivation of design ideas, rather than a specific sensor master degree.

3) Focus on teaching arrangement is on the basic theory, the basic principle, the actual design and the experiment, it is convenient for students to master and apply the knowledge, and to develop the students' ability of design and practice.

In order to adapt to the new teaching content, it will change the original teaching order:

1) In the introduction part, this paper particularly introduces the latest trends and development direction of optical fiber sensing technology.

2) Change the two chapters about the optical fiber and optical cable, common optical passive devices into the objective teaching in laboratory; enable students to have a sensory understanding of the devices commonly used in optical fiber sensing technology.

3) The two chapters of the sensing technology and modulation technology are taught in the classroom, and at the same time, each contents increases the actual application instances.

4) Combine the optical fiber temperature sensor and fiber grating sensor in teaching, at the same time 1 credit hours is added in this part for observing learning, introducing the latest cutting-edge scientific research achievements and distributed optical fiber sensing science research (distributed temperature sensing optical cable acquisition), as shows in Fig.1.

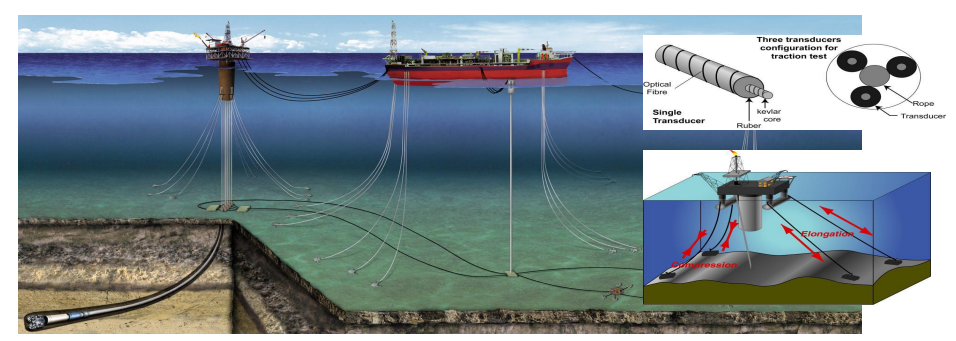

Fig.1 The latest research of distributed optical fiber sensing 
5) Use means of teaching and laboratory observation for the part of high voltage optical fiber current and voltage transformer, as shows in Fig.2.
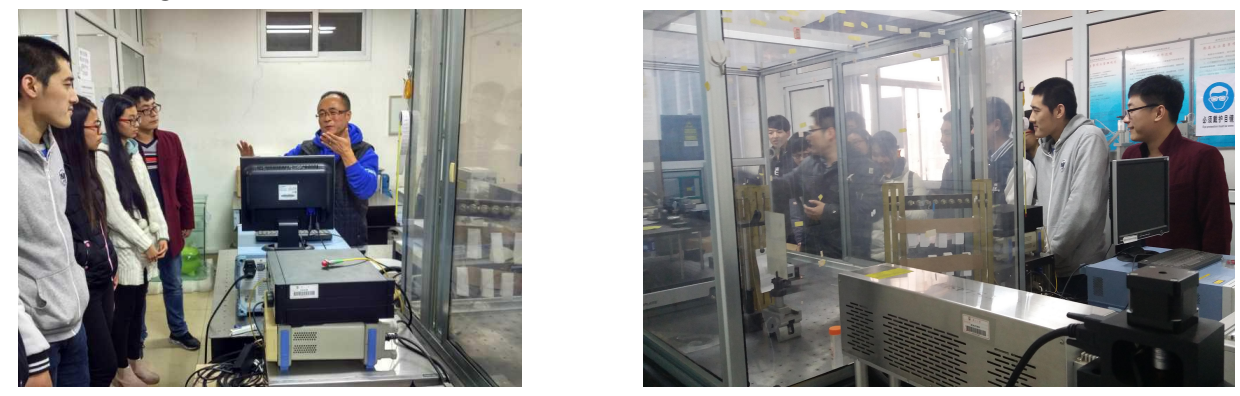

Fig.2 Teaching and Observation in Laboratory

6) Optical fiber mechanical quantity sensor part adopts the means of lectures combined with latest view and observation learning.

7) Other applications of fiber optic sensors using role exchange teaching, require students to use the knowledge previously learned to design and exploration, and then give a report[7], as shows in Fig. 3.


Fig.3 The role exchange teaching

Through the adjustment of the curriculum content, the old and new content contrast is as follows:

New: 14 credit hours for basic theories and principles, 4 credit hours for observation learning, 4 credit hours for experimental teaching, 2 credit hours for role exchange teaching and 4 weeks for case practical teaching (combined with professional comprehensive training, as shows in Fig.4.).
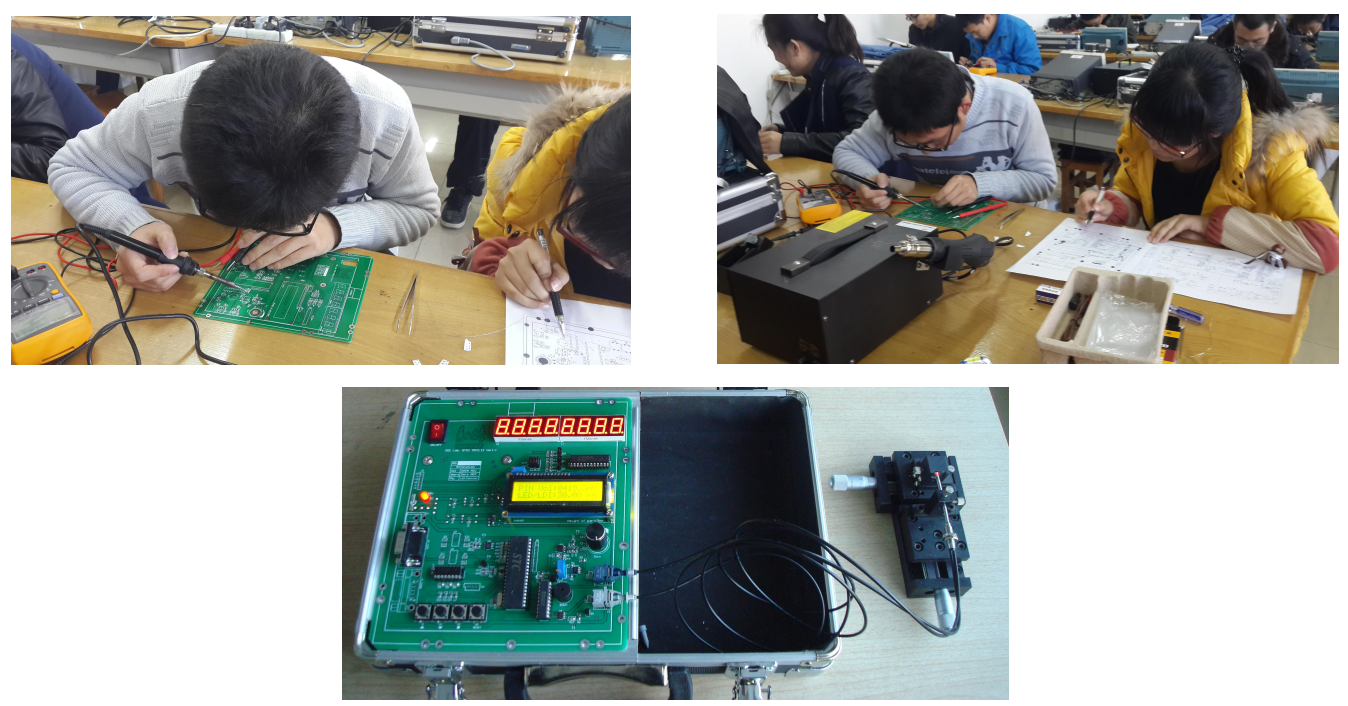

Fig.4 The professional comprehensive training 
Old: 20 credit hours for basic theories and principles and 4 credit hours for experimental teaching.

Specific details of the adjustment is shown in Table 1, and the reference materials are "optical fiber communications and sensing technology," edited by Professor Weihong Bi, projected materials for electronic information and electrical discipline, published by Electronic Industry Press.

Table 1: Contrast in content and credit hours a between he old and the new one

\begin{tabular}{|c|c|c|c|c|}
\hline $\mathrm{SN}$ & Content before reform & $\begin{array}{l}\text { Credit } \\
\text { hours }\end{array}$ & Content after reform and the specific innovation & $\begin{array}{l}\text { Credit } \\
\text { hours }\end{array}$ \\
\hline 1 & Introduction & 2 & $\begin{array}{l}\text { Introduction part (particular introduces the latest } \\
\text { trends in the field of optical fiber sensing } \\
\text { technology) }\end{array}$ & 2 \\
\hline 2 & Optical fiber and optical cable & 1 & Optical fiber and optical cable, Common optical & \\
\hline 3 & Common optical passive devices & 1 & $\begin{array}{l}\text { passive devices } \\
\text { Notation: this part will be taught in laboratory }\end{array}$ & 2 \\
\hline 4 & $\begin{array}{l}\text { Fundamentals of optical fiber sensing } \\
\text { technology }\end{array}$ & 4 & $\begin{array}{l}\text { Fundamentals of optical fiber sensing technology } \\
\qquad \text { (lecture) }\end{array}$ & 4 \\
\hline 5 & Fiber sensing modulation technology & 2 & Fiber sensing modulation technology (lecture) & 2 \\
\hline 6 & Optical fiber temperature sensor & 2 & $\begin{array}{l}\text { Optical fiber temperature sensor and fiber grating } \\
\text { sensor } \\
\text { (lecture \& latest view \& observation learning) }\end{array}$ & 3 \\
\hline 7 & $\begin{array}{c}\text { High voltage optical fiber current and } \\
\text { voltage transformer }\end{array}$ & 2 & $\begin{array}{l}\text { High voltage optical fiber current and voltage } \\
\text { transformer (lecture \& observation learning) }\end{array}$ & 1 \\
\hline 8 & Optical fiber mechanical sensor & 3 & $\begin{array}{c}\text { Optical fiber mechanical sensor } \\
\text { (lecture \& latest view \& observation learning) }\end{array}$ & 4 \\
\hline 9 & $\begin{array}{l}\text { Fiber Bragg grating sensor and its } \\
\text { application }\end{array}$ & 2 & $\begin{array}{c}\text { Other applications of optical fiber sensing } \\
\text { (role exchange teaching) }\end{array}$ & 2 \\
\hline 10 & $\begin{array}{l}\text { Other applications of optical fiber } \\
\text { sensing }\end{array}$ & 1 & Experiment I & 2 \\
\hline 11 & Experiment I & 2 & Experiment II & 2 \\
\hline 12 & Experiment II & 2 & $\begin{array}{l}\text { integrated case design (combined with professional } \\
\text { comprehensive training) }\end{array}$ & $\begin{array}{c}4 \\
\text { weeks }\end{array}$ \\
\hline
\end{tabular}




\section{TEACHING METHOD}

In teaching, in order to make the students master the knowledge easily and improve their comprehensive design and practice ability extend the classroom teaching to the actual development and design process. According to the characteristics of the course, teaching is by the following ways:

1) In the aspect of common teaching in classroom, we should break the original single injection teaching method, adopt flexible and various heuristic teaching methods, pay attention to the interaction between teachers and students and the cultivation of students' practical ability. The basic content is given by the teacher, the actual case is done based on teacher-student interaction, and the specific design is hands-on by students. From the operational level of teaching, it will completely subvert the original teaching methods, and form a new teaching model.

2) Using multimedia teaching method, make network resources as a useful complement to classroom teaching. Multimedia teaching can achieve the effects as following: (1) It can integrate sound, light, shape, color, motion, etc. during explaining, and can greatly stimulate students' interest in learning.(2) By multimedia animation demonstration, it leads teaching more intuitive and interactive, and greatly accelerate the speed of teaching.

3) Combine classroom teaching with practice teaching: It can be divided into 4 levels: classroom teaching, observation learning, comprehensive design and experimental teaching. Draw inferences about other cases from one instance to strengthen their practical ability.

\section{IMPLEMENTATION OF NEW TEACHING METHODS}

The new teaching mode is demonstrated by the group of curriculum reform, and is implemented according to the plan after being approved by the leaders of college and the office of academic affairs, the specific implementation process is as following:

The first stage is about the basic theory of optical fiber sensing technology teaching, mainly to study the basic theory of optical fiber sensing technology and modulation \& demodulation technology, to enable students master the basic theoretical knowledge;

The second stage is the introduction of the basic working principle of the common optical fiber sensor, using discussion method, by teacher-student interaction to changed the situation of monodrama played only by the teacher in the past and then to make students actively exploring instead of passively accepting knowledge intonation. In order to organize the content of discussion, teachers should design the outline for discussing before class according to the content designed by students, and guide the discussion process.

The third stage is the observation learning stage, firstly the teacher raises some questions, then students preview and access to relevant knowledge, finally they visit the site with questions, thus increase their perceptual knowledge. After they understand the actual operation methods, the teacher can carry on the rational analysis and summary, explain the key points, difficulties, and solve the problem.

In the fourth stage of practice teaching, on the basis of the above three stages, we should allow full to play the students' comprehensive innovation and practical ability, and lay a good foundation for their future developing on practical application system. 


\section{CONCLUSION}

Through the reform of the content, the form and the teaching method of the optical fiber sensing technology course, the students can learn and master the relevant knowledge of the optical fiber sensing technology effectively, understand the latest development of the technology, have the ability to design and debug optical fiber sensing system independently; fully manoeuvre their interest in learning from passive accepting to active learning; supply the chance of comprehensive training to them, and further improve the ability to comprehensively applicable knowledge, so that make the course of optical fiber sensing technology really play a role in cultivating students' innovative ability and practical ability.

\section{REFERENCES}

[1] Zhun Zhang, Liyun Zhong, "Design and Practice of Optoelectronic Technology Experiment Course Based on CDIO Concept," Laboratory Research and Exploration 31(8), 367-370 (2012).

[2] Tongping Han, Qingyou Wang, "College optoelectronic specialty should cultivate talents to meet the needs of enterprises," Industrial and Informational Education 2, 75-78 (2013).

[3] Lianfa Yang, Ya Zhou, Weiqi Liao, etc, "Discussion on the Current Situation of Comprehensive Training of Engineering Specialty and the Reform of Practice Mode," China Modern Educational Equipment 1, 90-92 (2011).

[4] Chunyan Yang, Chao Wu, Rumin Zhu, "On the Teaching Reform of Sensor Technology Course," China Modern Educational Equipment 3, 104-105 (2010).

[5] Haiyan Wu, "Factors and Countermeasures of Inadequacy of Practical Ability of College Students," Statistics and Management 6, 84-85 (2015).

[6] Fengyan Dai, Jianshu Cao, "Design and Practice of Optoelectronic Technology Experiment Course Based on CDIO Concept," Laboratory Research and Exploration 5(30), 88-90 (2011).

[7] Miaosun Cao, Zhixing Liang, "The Role Transformation of Engineering Teachers Based on CDIO Concept," Research on Higher Engineering Education 1, 88-91(2012). 